\title{
Primary pulmonary hypertension in leopard syndrome
}

\author{
LEONARD C BLIEDEN, A ADAM SCHNEEWEISS, HENRY N NEUFELD \\ From the Heart Institute, Chaim Sheba Medical Center, Sackler School of Medicine, Tel Aviv University, \\ Tel Aviv, Israel
}

SUMMARY The leopard (cardiocutaneous) syndrome consists of multiple lentigines, congenital cardiac anomalies, ocular hypertelorism, electrocardiographic abnormalities, abnormalities of genitalia, retardation of growth, and deafness. We describe what we believe to be the first case associated with primary pulmonary hypertension.

The leopard, or cardiocutaneous syndrome, includes various congenital malformations affecting the skin, the cardiovascular system, the inner ear, the genitalia, and growth. ${ }^{12}$

Pulmonary stenosis, usually resulting from atypical or dysplastic pulmonary valve, is the most common congenital cardiac lesion associated with this syndrome, though hypertrophic cardiomyopathy and other lesions have also been described. ${ }^{1-3}$

We describe a case of leopard syndrome with primary pulmonary hypertension and no congenital cardiac anomaly. To the best of our knowledge this association has not previously been reported.

\section{Case report}

A 6-year-old girl was referred to the Heart Institute, of the Chaim Sheba Medical Center for evaluation of episodes of dyspnoea which appeared three months before admission. A heart murmur was heard two years earlier. On examination she was thin and relatively short for her age $(18 \mathrm{~kg}, 110 \mathrm{~cm}$, approximated 10th centile for both). She had multiple pigmented naevi up to $5 \mathrm{~mm}$ in diameter on her face, trunk, and limbs. Her mother had similar naevi. Mandibular prognathism, ocular hypertelorism, and darkly pigmented iris were prominent. She was mildly dyspnoeic but there were no signs of congestive heart failure. The heart rate was $100 / \mathrm{min}$, and blood pressure $110 / 70 \mathrm{mmHg}$. A prominent right ventricular impulse was palpated. On auscultation, the first heart sound was normal, and the second heart sound was very closely split with an accentuated pulmonary component. No ejection click or murmur were audible.

^Present address: Pediatric Cardiology Unit, Heart Institute, Beilinson Medical Center, Israel.
The electrocardiogram showed a frontal plane QRS axis of a $110^{\circ}$ and right ventricular hypertrophy. Thoracic radiography showed a raised cardiac apex, right ventricular enlargement, prominent main pulmonary artery, and normal pulmonary vasculature.

Echocardiography (Fig. 1) showed a normal left heart and signs of pulmonary hypertension with increased pulmonary vascular resistance: the pulmonary valve echogram had no " $a$ " wave, and a

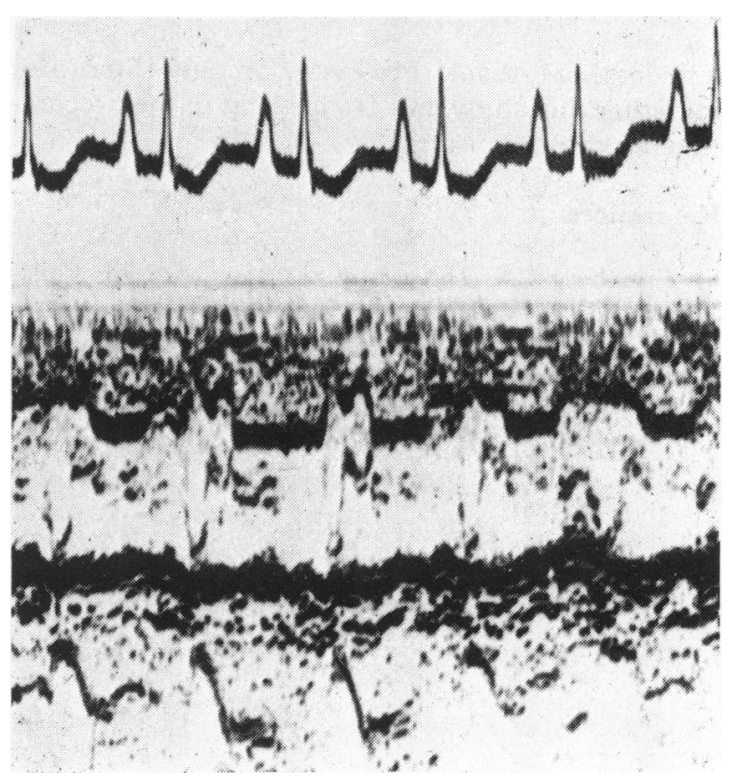

Fig. 1 Echocardiogram showing a mid-systolic notch with $a$ "flying $W$ " pattern of the pulmonary valve, and absence of an " $a$ " wave. 
mid-systolic notch and a "flying W" pattern of the valve were present. At cardiac catheterisation no shunt was found. The cardiac index was $2 \cdot 11 / \mathrm{min}$ per $\mathrm{m}^{2}$. The right ventricular pressure was $130 / 80$ $\mathrm{mmHg}$, the main pulmonary artery pressure was $130 / 80 \mathrm{mmHg}$ (mean 105), the wedge pressure was $8 \mathrm{mmHg}$, and the aortic pressure $110 / 70 \mathrm{mmHg}$ (mean 90). During the catheterisation ventricular extrasystoles appeared, and because of the wellknown risk of sudden death in patients with primary pulmonary hypertension angiocardiography was not performed.

Skin biopsy disclosed typical lentigenes with hyperactive melanocytes and prominent rete ridges penetrating into the dermis. The diagnosis was leopard syndrome with primary pulmonary hypertension.

Subsequently the patient's clinical condition deteriorated. She developed congestive heart failure and syncope on effort. At the same time the lentigenes increased in number and extent. She died at 8 years of age of a syncopal attack.

Necropsy disclosed no primary congenital cardiac anomaly. The right ventricle was hypertrophied and dilated. Histological sections of the lungs showed typical features of the pulmonary arteries in severe primary pulmonary hypertension ${ }^{4}$ : medial hypertrophy, intimal fibrosis, fibrinoid vascular necrosis, necrotising arteritis, and plexiform lesions (Fig. 2).

\section{Discussion}

Leopard syndrome is the term coined by Gorlin and his colleagues ${ }^{1}$ to describe children with lentigenes and a complex of congenital malformations. The term "leopard" describes the external appearance of the patients with multiple pigmented naevi, and each letter of the word represents a feature of the syndrome. ${ }^{12}$

Our case showed several of the main characteristics of leopard syndrome, but not pulmonary stenosis, deafness, or primary cardiac anomaly. This is the first report on leopard syndrome associated with primary pulmonary hypertension. The histological sections showed the typical picture of

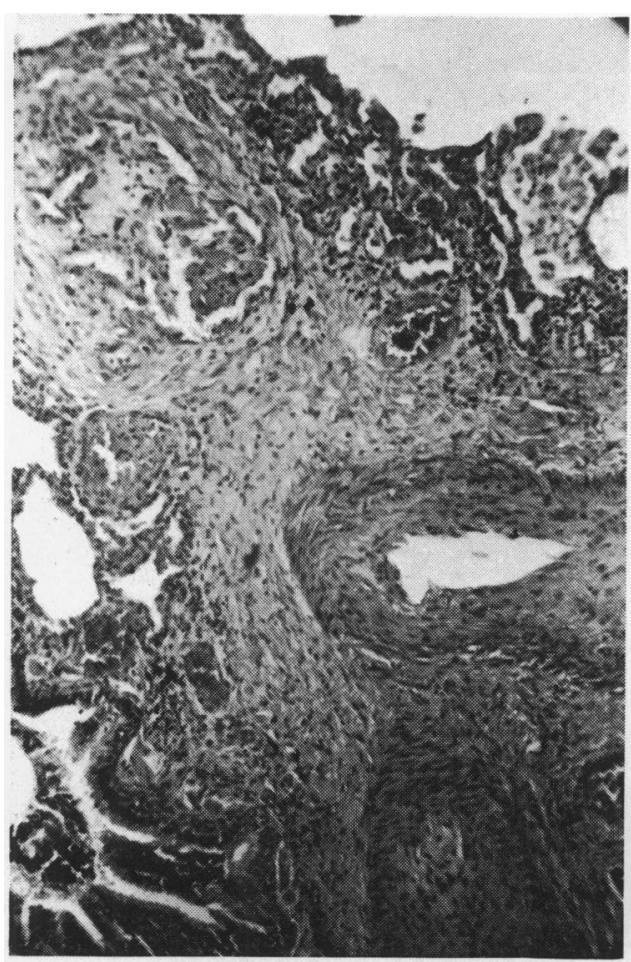

(a)

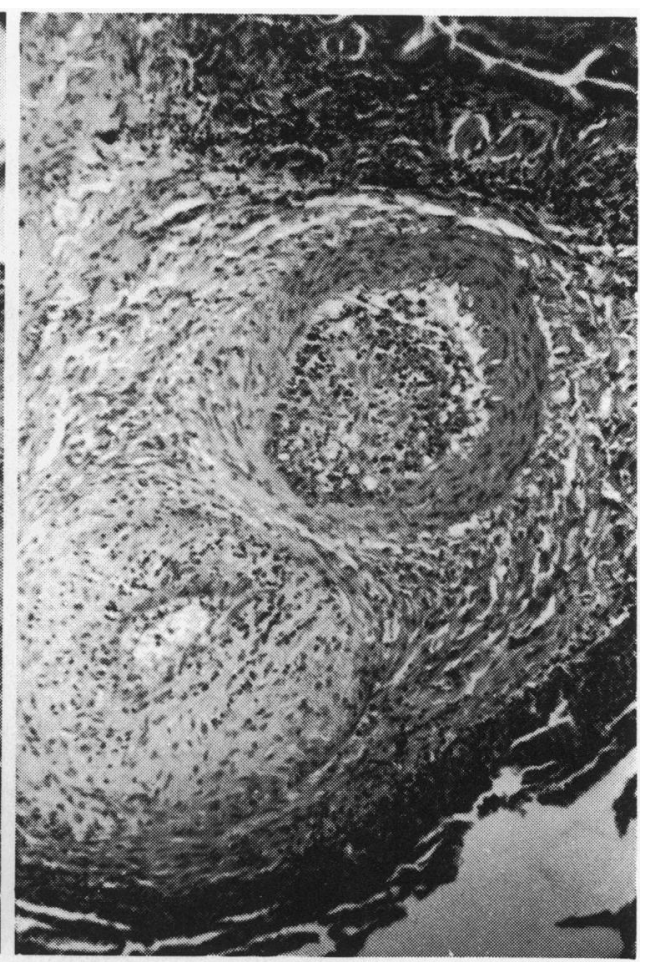

(b)

Fig. 2 Histological sections of the lungs $(a, b)$ showing medial hypertrophy, intimal fibrosis, and fibrinoid vascular necrosis of the pulmonary arteries with plexiform lesions. 
vasoconstrictive pulmonary hypertension. ${ }^{4}$

It is not clear whether this association is merely a coincidence or a result of the basic pathogenic mechanism of the syndrome. Wagenvoort et al. ${ }^{4}$ suggested that the initial cause of primary pulmonary hypertension was pulmonary vasoconstriction that results later in histological changes. Polani and Moynahan ${ }^{3}$ suggested that the melanocytes of the lentigenes that originate from the neural crest and whose melanin metabolism is related to catecholamine metabolism may secrete some abnormal vasoactive amine. This amine might cause pulmonary vasoconstriction which could then lead to pulmonary hypertension. An alternative hypothesis ${ }^{3}$ attributes both the lentiginosis and the hypertrophic cardiomyopathy in these patients to a genetic anomaly in cells of neural crest origin present in the cardiac muscle as well as the lentigenes. Cells of neural crest derivation are, however, also present in the walls of the blood vessels. A genetic anomaly in these cells may cause pulmonary vasoconstriction leading to primary pulmonary hypertension.
The authors acknowledge the help given by Dr C Kaplinsky.

\section{References}

1 Gorlin RJ, Anderson RC, Blaw M. Multiple lentigenes syndrome. Am $\mathcal{F}$ Dis Child 1969; 117: 652-62.

2 Somerville J, Bonham-Carter RE. The heart in lentiginosis. Br Heart $\mathcal{F} 1972$; 34: 58-66.

3 Polani PE, Moynahan EJ. Progressive cardiomyopathic lentiginosis. $Q$ f Med 1972; 41: 205-25.

4 Wagenvoort CA, Heath D, Edwards JE. The pathology of the pulmonary vasculature. Springfield, Illinois: Charles C Thomas, 1962: 61-4.

Requests for reprints to Dr Adam Schneeweiss, Heart Institute, Sheba Medical Center, Tel Hashomer, Israel. 